\title{
AIR EMBOLUS IN NEUROSURGICAL ANAESTHESIA, ITS DIAGNOSIS AND TREATMENT
}

\author{
Brian M Marshall, M D, F R C P $(\mathrm{C})$ *
}

WITH THE INTRODUCTION of controlled positive-negative-pressure ventilation in neurosurgical anaesthesia, our attention was focused upon the possibility that the technique might cause aur embolism In order to facilitate the early detection of an aur embolus, the use of an oesophageal stethoscope, as described by $\mathrm{C}$ Smith, ${ }^{1}$ was instituted as an additional monitoring device This paper describes the occurrence of six cases of aur embolism, two of which occurred in the same patient from different sites, and will discuss the diagnosis, clinical course, and treatment The cases are taken from a 26-month period, during which time there was a lotal of 281 cases in the categories in which it was thought that air embolism might occur These groups are outlined in Table I

TABLE I

\begin{tabular}{lcccc}
\hline \hline & $\begin{array}{c}\text { Posterior } \\
\text { fossa } \\
\text { exploration }\end{array}$ & Craniotomy & \multicolumn{2}{c}{$\begin{array}{c}\text { Cervical } \\
\text { laminectomy hypothermia } \\
\text { with }\end{array}$} \\
\hline Position & Sitting & Supine & Prone & Supine \\
Total number & 34 & 16 & 37 & 49 \\
Incidence of air embolus & 5 & -1 & 1 & $\frac{100 \%}{\text { Positive and negative controlled ventilation }}$ \\
\hline
\end{tabular}

The anaesthetic technique varied only slightly in each group of cases Induction of general anaesthesia with thiopentone was followed by intubation, anded by succinylcholine relaxation Nitrous oxide, and oxygen plus halothane, were used as the basic anaesthetics Controlled ventulation with intermittent positive and negative pressure was used when surgical or anaesthetic factors so indicated Controlled ventilation was not used for any cases in the sitting position, it was usually used for intracranial tumours with the patient in other positions, and it was always used in conjunction with hypothermia

The cases are described in Table II Cases 1, 2, and 5 involved patients undergoing posterior fossa exploration in the sitting position Each patient was breathing spontaneously In each case the air embolism occurred during the surgical exposure while bone was being removed Case 3 was a patient with a tumour of the upper mediastinum in whom a decompression of the lower cervical and upper thoracic spinal cord was being carned out The patient was in the prone position In this case the aur entered by a vein in the fascia overlying the thoracic lamina The vein was held open by a self-retaining retractor Air embolism

- Department of Anaesthesia, University of Toronto and Toronto General Hospital, Toronto, Ontario Presented in part at the Annual Meeting of the Canadian Anaesthetists' Society at Montebello, May, 1964 
occurred on two occasions in patient 4, ruthally during the surgical exposure, and subsequently after the bone had been removed This patient was undergoing re-exploration for a posterior fossa tumour which had been removed initially about seven years previously

The initial diagnostic feature noted in five of the six instances was the sound of air in the cardiac chambers, as described in Table III In the other instance, the oesophageal stethoscope was not in use at the moment when the embolus occurred Of special interest is the amoint of time which elapsed in each case between the initial diagnostic sign and uny change in cardiovascular or respiratory function The rapidity of onset and the magnitude of the change in cardiac or respiratory function appeared to be associated with the rapidity of entry into, and the arnount of air trapped $\mathrm{m}$, the heart chambers

TABIE II

\begin{tabular}{|c|c|c|c|c|c|}
\hline & Case 1 & Case 2 & Case 3 & $\begin{array}{c}\text { Case } 4 \mathrm{~A} \\
\text { and } 4 \mathrm{~B}\end{array}$ & Case 5 \\
\hline $\begin{array}{l}\text { Operative } \\
\text { procedure }\end{array}$ & $\begin{array}{l}\text { Post fossa } \\
\text { exploration }\end{array}$ & $\begin{array}{l}\text { Post fossa } \\
\text { exploration }\end{array}$ & $\begin{array}{l}\text { Lower cervical } \\
\text { and upper } \\
\text { thoracic cord } \\
\text { dec ompression }\end{array}$ & $\begin{array}{l}\text { Post fossa } \\
\text { exploration }\end{array}$ & $\begin{array}{l}\text { Post fossa } \\
\text { exploration }\end{array}$ \\
\hline \multirow{3}{*}{$\begin{array}{l}\text { Position } \\
\text { Spontaneous } \\
\text { respiration } \\
\text { Anaesthetic } \\
\text { risk }(1-5)\end{array}$} & Sitting & Sitting & Prone & Sitting & Sitting \\
\hline & Yes & Yes & Yes & Yes & Yes \\
\hline & 2 & 1 & 2 & 1 & $\mathbb{1}$ \\
\hline
\end{tabular}

TABLE III

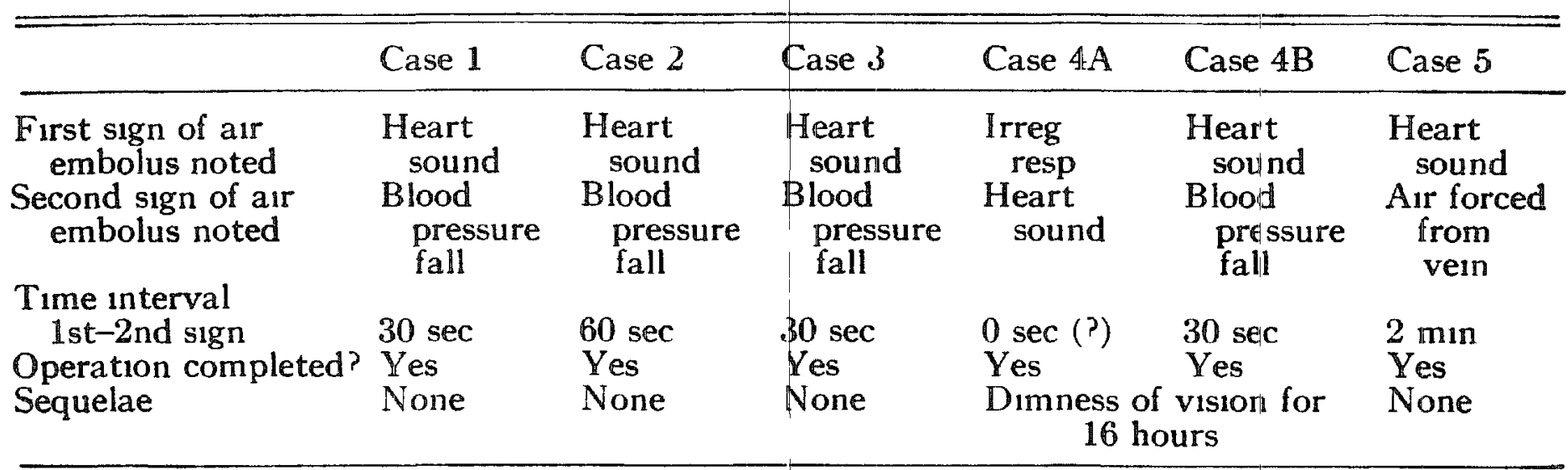

The clinical course in each instance was similar The unitial sound of air in the heart was followed by a drop in blood pressure There was always a measureable period of time between these two events It was possible in each case, except of course case $4 \mathbb{B}$, to record a "normal" blood pressure at least once before any decrease in systolic reading was noted This was followed by a varying degree of hyperpnoea, or on some occasions by tachycardia, and u regular cardiac rhythm The duration and extent of the cardiovascular and respuratory dysfunctions varied with the general condition of the patient, the rapidity and effectiveness of the treatment, and also, we assume, with the amount of aur in the heart chambers 
The management of these cases was not complicated, and required no special apparatus The steps are outlined in Table IV As soon as the diagnosis was made, the surgeon was advised and requested to cover the area in which he was working, in order to prevent the entrance of more aur At the same time the anaesthetic expuratory valves were closed, and/or pressure was applied to the jugular veins This resulted in air being forced fron the open vein In each case the site of entrance of the all was confirmed in this manner It was then necessary to remove the air from the heart chamber and to mantain adequate cardiovascu-

TABLE IV

\begin{tabular}{|c|c|c|c|c|c|c|}
\hline Treatment & Case 1 & Case 2 & Case 3 & Case 4A & Case $4 \mathrm{~B}$ & Case 5 \\
\hline Positive pressure & Yes & Yes & Yes & Yes & Yes & Yes \\
\hline External cardiac massage & No & No & No & Yes & No & No \\
\hline Position change & $\begin{array}{l}\text { Sitting to } \\
\text { lateral }\end{array}$ & No & $\begin{array}{l}\text { Horizontal } \\
\text { to head- } \\
\text { down }\end{array}$ & $\begin{array}{l}\text { Sitting to } \\
\text { lateral }\end{array}$ & $\begin{array}{l}\text { Sitting to } \\
\text { lateral }\end{array}$ & No \\
\hline Vasopressor & Yes & Yes & Yes & Yes & Yes & No \\
\hline
\end{tabular}

lar function On one occasion nothing was required other than to prevent further air from entering the vein On another occasion a small amount of vasopressor only was required To remove the air from the right side of the heart it was jound adequate simply to increase venous return by moving the patient to the honzontal or head-down position In those patients who were in the sitting position, it was possible, because of a special arrangement described below, to place them in the lateral-horizontal position The resulting increase in venous return was sufficient to clear the air from the heart quickly This manoeuvre was equally effective in either the right or left lateral position. A vasopressor drug was sometimes given When the cardiovascular function became stable, the patient was returned to his previous position and the operation continued

The clinical course in each case was, we hope, altered by the treatment In five cases the diagnostic sound preceded by 30 seconds or more any change in cardiovascular function In the one case in which the stethoscope was temporarily not in use, the diagnosis was made on the basis of the sound of arr in the heart after the occurrence of tachypnoea and drop in blood pressure This patient was the only one in whom possible sequelae occurred

\section{Discussion}

The ease and accuracy of diagnosis came as rather a surprise Reference texts imply that a diagnosis of cardiac air ernbolism is made mainly on the basis of cardiovascular collapse, or signs of gross respiratory insufficiency ${ }^{2}$ The presence of a "millwheel" type of cardnac murmur has been regarded as pathognomonic of the condition ${ }^{3}$ In all cases that we have noted, the only constant sign has been the murmur described In five of the six instances it was the initial and diagnostic sign There have been no false positive diagnoses, nor, we feel, have there been any occasions when the presence of aur 1 in the heart chambers was not detected while the stethoscope was being used 


\section{The Modffed Sitting Position}

The ease and rapidity with which the patient could be moved from the sitting to the lateral recumbent position are due to the technique described by Frances Garcia Bengorhia in 1962 at the 15th Annual Meetung of the Neurosurgical Society of Amenca. ${ }^{4}$ The patient is placed in a legless armchaur or other sutable supporting frame facing sideways on the operating table The cephalic end of the table is elevated to the vertical position and the charr is placed flush with thus support The head frame may be attached to this portion of the table The surgical draping is done so that the patient is draped free of the instrument tables The charr and patient are then strapped firmly to the vertical portion of the operating table To place the patient in the lateral recumbent position it is necessary merely to rotate the enture table through 90 In this way the patient does not change position relative to the table nor is the draping disturbed The surgeon still has full vew of the operating field and he can contmue any urgent or emergency measures albeit with mcreased difficulty (see Figs 1 to 4)

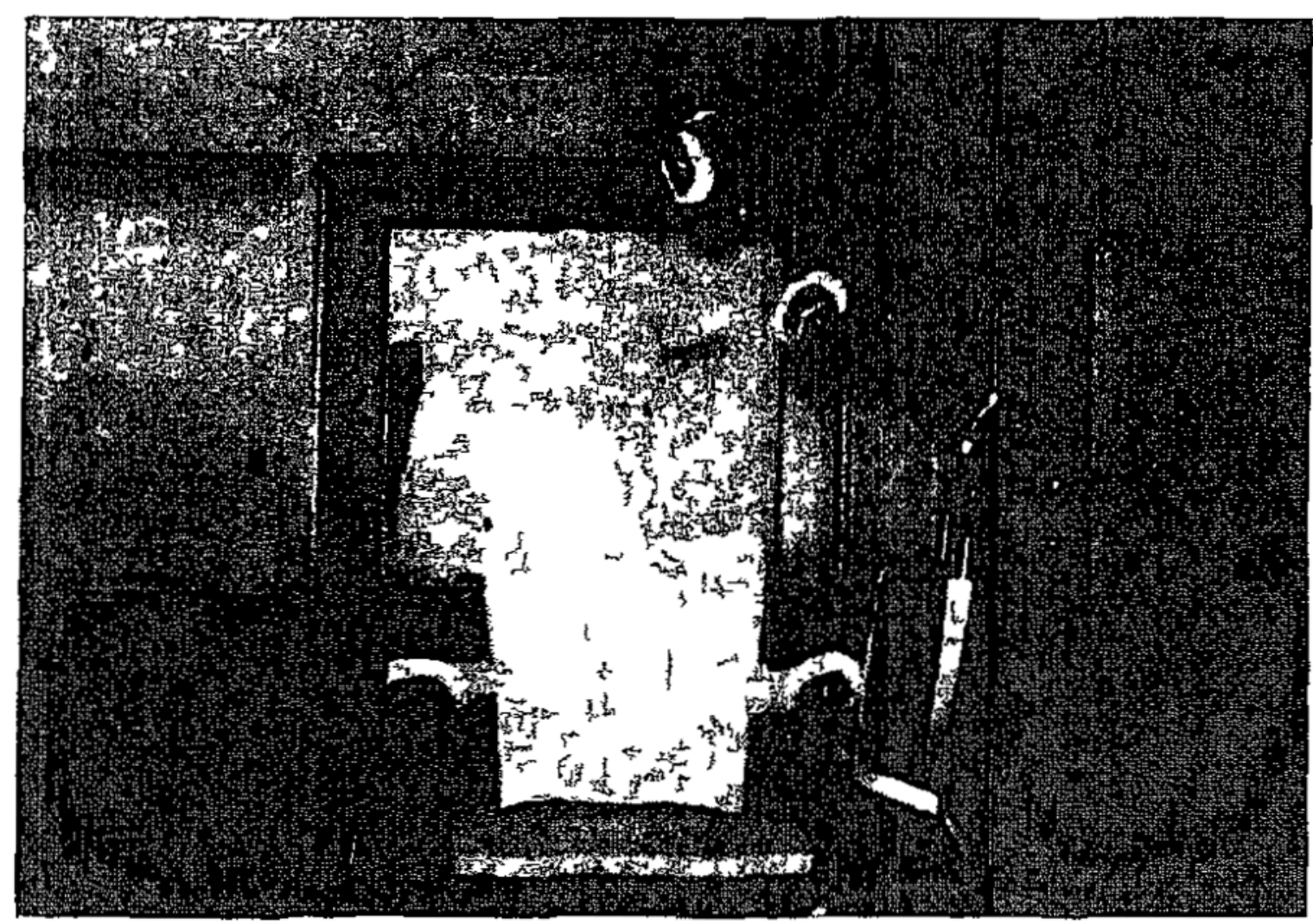

Frgure 1 Operatong table chaur and $f$ ame

\section{Conclusiov}

We have found arr embolism to occur in neurosurgical operations unvolving exploration of the posterior cranial fossa or posterior cervical region The embolus may occur when the patient is in exther the prone or sitting position $W e$ have not found an air embolusm associated with operations on the anterior or middle cramial fossae the cervical spine using the antenor approach or the lumbar spine either with or without the use of positive negative controlled ventilation

We have found that the endo oesophageal stethoscope gives an instantaneous 


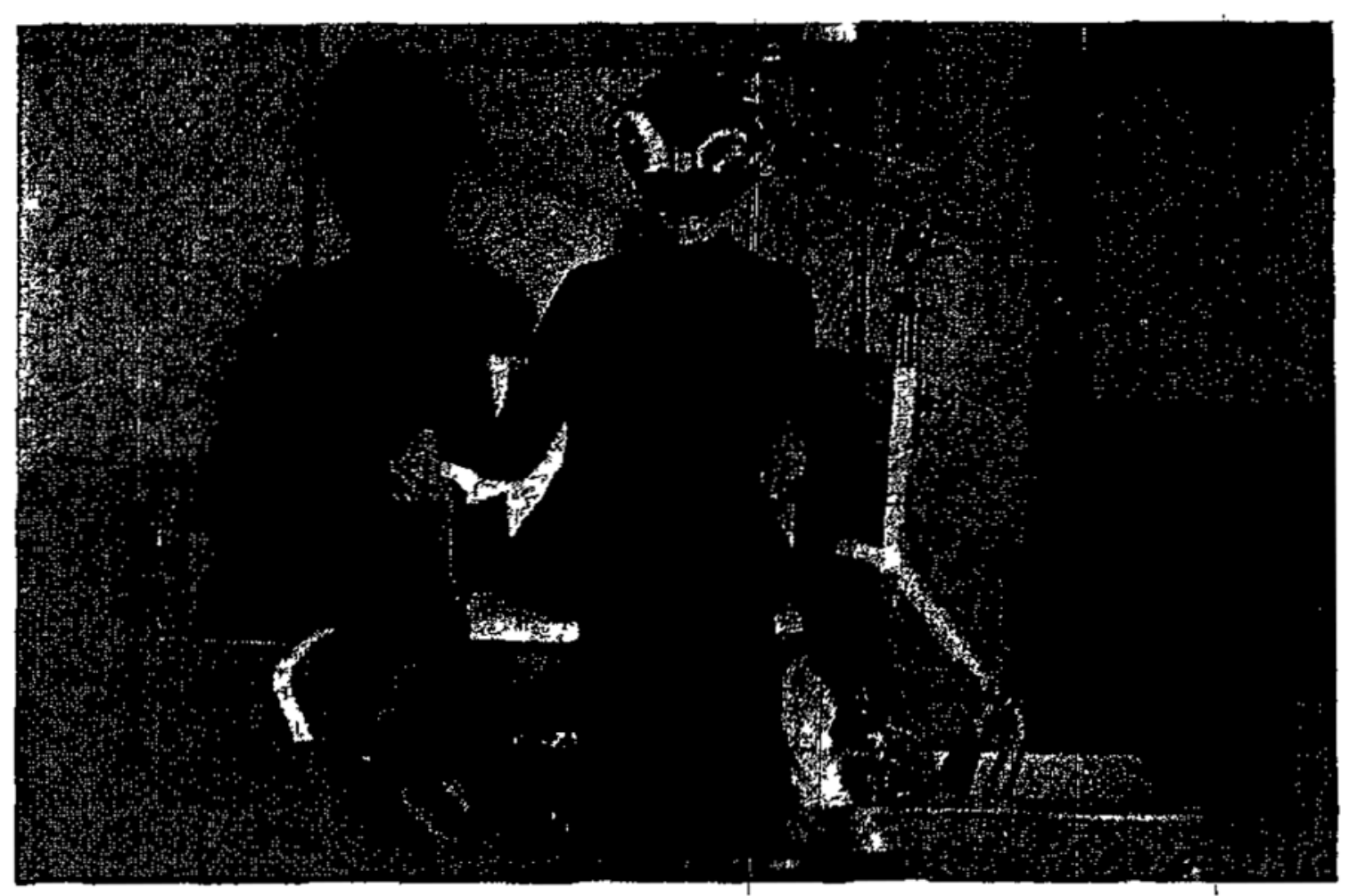

Ficure 2 Position lof patient

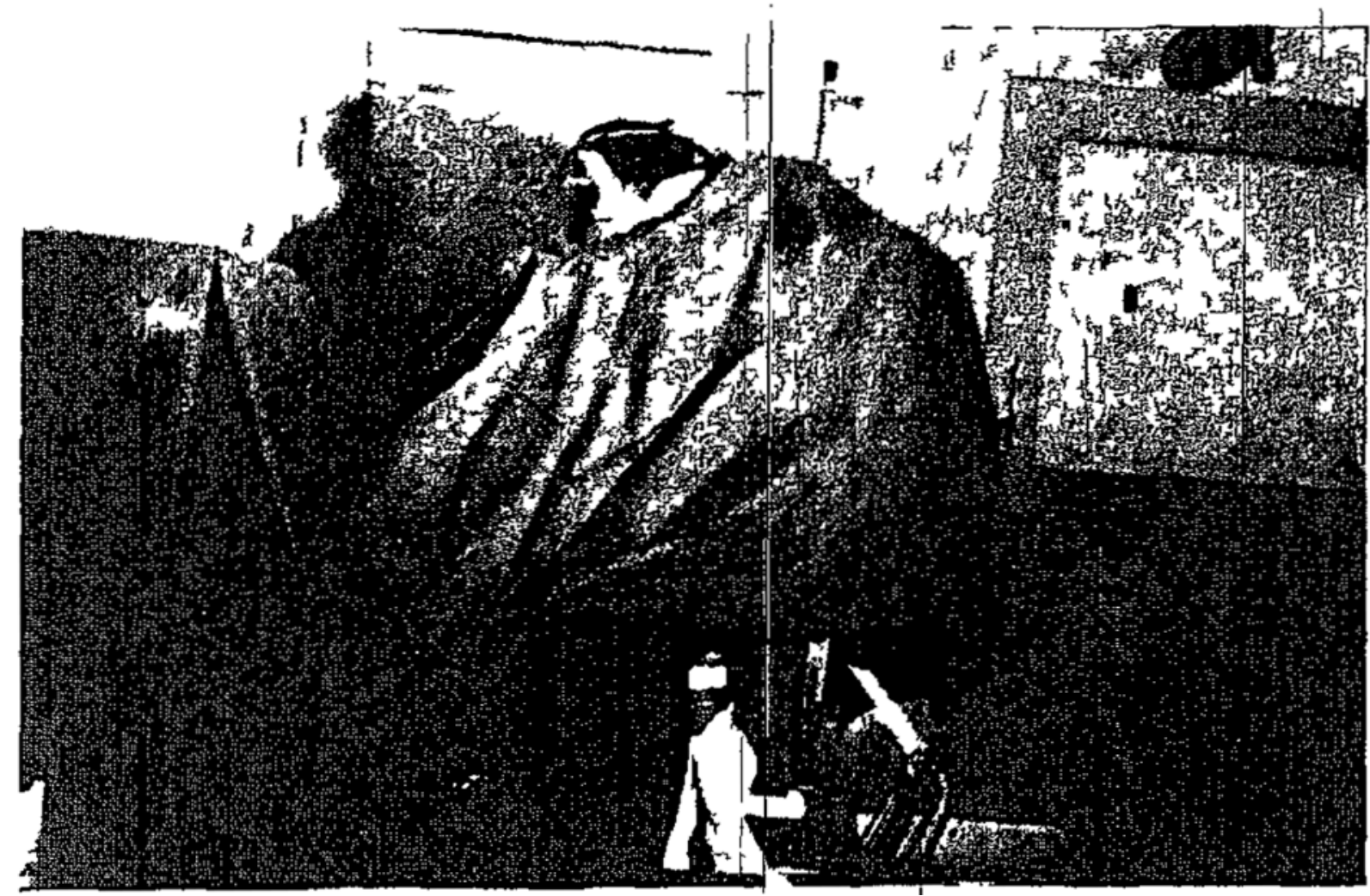

Figuhe 3 Patient draped with head draping pulled asıde

and accurate diagnosis of the presence of aur 10 the heart Our treatment of these case which has been completely successful is as follows

1 Prevent further entry of air into the vem

2 Force all aur out of the vein by jugular compression and/or by mcreasing intrathoracic pressure

3 Wash air out of the heart into the lung by moreasing greatly the blood flow from the infenor vena cava This is done by changing the position of the patient 


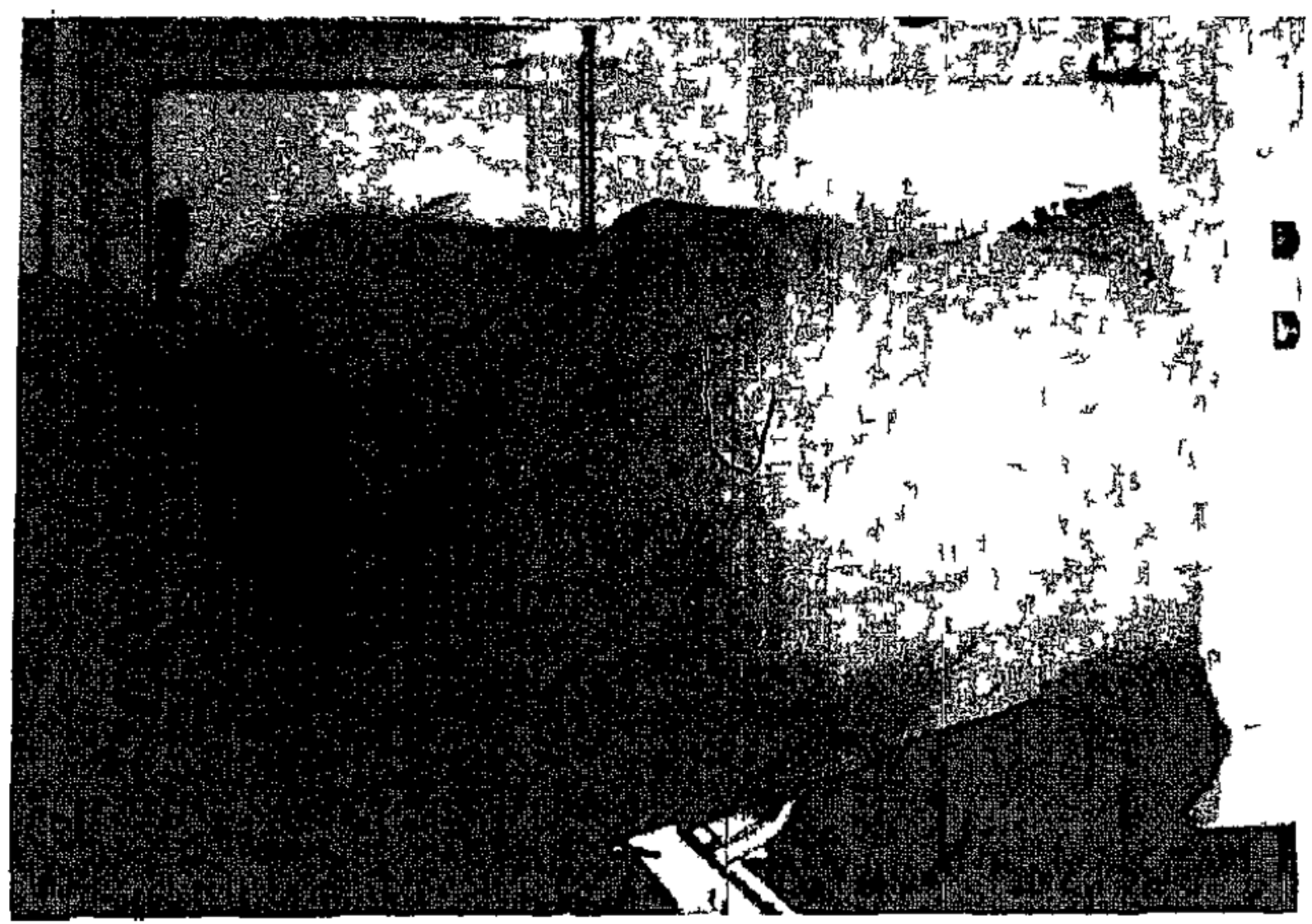

Frgune 4 Patient and table in lateral position

from the sittung to the lateral recumbent position or from the prone to the head down position

4 Use measures to support cardiovascular and respiratory function such as vasopressors and ventilation with pure oxygen

\section{SUMMARY}

Six cases of aur embolus were noted in a total of 218 neurosurgical procedures over a penod of 26 months The operations uncluded craniotomies posternor and middle fossa explorations cervical laminectomies and upper thoracic and cervı cal spine explorations Five cases occurred with the patient in the sitting position and one in the prone position No case occurred in conjunction with the use of positive-negative controlled ventilation

It was found that the use of an endo oesophageal stethoscope afforded an immediate and accurate diagnosis of this condition Changes in respiratory and cardiovascular function followed at least 30 seconds after the earliest evidence was noted by means of the oesophageal stethoscope

The treatment of the cases consisted of preventing more aur from entering through the open vein washing the alr out of the heart chambers by increased venous return and supporting cardrovascular and respiratory function where necessary By a special positioning arrangement it is possible to move the patient from the sitting to the lateral position without disturbing the draping or the operatuve field As a result of this all operations were continued after a short delay and concluded successfully

It is suggested that an endo-oesophageal stethoscope be used whenever it is considered possible that cardiac air embolism may occur 


\section{RÉSUMÉ}

Depurs plusieurs années, nous nous sommes servis d'un stéthoscope oesophagien comme instrument pour dépister les embolies gajeuses cardiaques dans tous les cas d'anesthésie pour neurochirurgie

$\mathrm{Au}$ cours des 26 premiers mois, nous avons diagnostıqué six cas d'ambolie gazeuse Cinq de ces cas sont survenus au cours de la chirurgie pour exploration de la fosse postérieure alors que le malade étant en position assise L'autre cas est survenu au cours d'une décompression de la moelle cervicale et thoracique haute, le malade était en position ventrale Aucun de ces cas n'est relıé à l'usage de la venulation controlée avec pression positive et négative

Nous avons entendu le brut de l'embolie gazeuse dans le cœur, chez 5 des 6 cas, au moins 30 secondes avant l'observation de tout autre signe Dans un cas, le stéthoscope n'était pas en usage pour un moment, lorsque l'embolne est survenue La porte d'entrée de l'air a été retrouvée dans chaque cas, en faisant ressortur des bulles d'air, soit en augmentant la pression dans le curcuit de la machine à anesthésie, soit en comprimant les veines du cou

Comme traitement, nous avons fermé l'entrée de l'aur dans le champ opératoure el nous avons chassé l'aur des chambres cardraques en augmentant le retour du sang veineux venant de la partıe inférneure du corps Pour réaliser ce tratement, Il nous a suffi de placer le malade la tête basse et/ou en position latérale Occasionnellement, nous avons dû recounr à des vasopresseurs pour rétablir la pression artérielle

\section{REFERENCES}

1 SMrtH, C An Endo-oesophageal Stethoscope Anesthebılogy 15566 (1954)

2 Wylite, W D, \& Chuncirll-Davioson, $H$ D A Practice of Anaesthesia, ist ed I,ondon Lloyd-Luke (1960)

3 WhitBy, J D Electrocardiography during Postenor Fossa Operations Brit J Anaesth 25624 (1963)

4 Garcia-Bengorhia, F Lateral Sitang Position for Postemor Fossa Exploration and Cervical and Upper Thoracic Cord Surgery Presented at the 15th Annual Meeting of The Neurosurgical Society of America, March 22, 1962 